\title{
EXPERIMENTAL EVALUATION OF MERCURY RELEASE FROM MOLTEN LEAD*
}

\author{
by \\ N. K. Tutu, G. A. Greene, and G. J. Van Tuyle \\ Brookhaven National Laboratory \\ Upton, New York 11973
}

\begin{abstract}
In order to assess the worst-case impact of an extremely improbable accident in an accelerator target for producing tritium, an event scenario was developed and analyzed, and an experiment was performed to resolve an important question raised by the analysis. The target, known as SILC for "Spallation Induced Lithium Conversion," contains approximately 22 metric tons of $\mathrm{Pb}$, with small inventories of potentially hazardous radionuclides which continue to accumulate as the production cycle continues. Analysis of a scenario involving several failures in the normal, backup, and emergency cooling systems is presented, including event simulation by BNL indicating when and how long the $\mathrm{Pb}$ continues to melt, and a summary of SNL estimates of the releases of potentially hazardous spallation products is given. Finally, a recent experiment is described in which it was shown that virtually no mercury is likely to escape from the molten $\mathrm{Pb}$, a result having significant impact on the potential risk of such worst-case scenarios.

\section{Background}

\subsection{Introduction}

As part of the Programmatic Environmental Impact Statement (PEIS) submittal for APT, a postulated beyond-design-basis-event (BDBE) accident analysis has been performed for the SILC target system in order to develop a bounding estimate for the release of spallation products from a damaged spallation target. The source-term estimate was based upon the predicted thermal response of the APT SILC spallation target to an unmitigated large-break loss-of-coolant-accident (LBLOCA) in the cold leg outside the target cavity. All active cooling systems were assumed to fail, including the Source Primary Cooling System (SPCS), Source Secondary Cooling System (SSCS), Source Blanket Primary Cooling System (SBPCS), Residual Heat Removal System (RHR), and the Target Cavity Cooling System (TCCS). In addition, it was assumed that passive cooling would fail as well, i.e., natural circulation would not be established in the unbroken loop of the SPCS although this is the design basis for the SPCS. The only plant protection systems that were credited were the accelerator beam trip, SPCS pump trip, and target cavity flood system. Details of the thermal-hydraulic analysis for the APT PEIS BDBE accident scenario will not be given here. The details will be available instead in a separate report which is under preparation. For completeness, the following discussion has been reproduced from the APT/SILC design report to illustrate the progression of the accident.

* This work performed under the auspices of the U.S. Department of Energy.

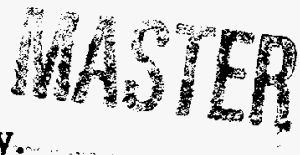


1.2 Large-Break Loss-of-Coolant Accident (LOCA): Total Failure of Active Cooling Systems Plus Non-Mechanistic Failure to Establish Natural Circulation in the Unbroken Loop, Cavity Heat Exchanger Non-Functional

The only system that is assumed to function is the Target Cavity Flood System. It is postulated that natural circulation (bulk flow through the pressure tubes) in the unbroken loop would not be established. The probability of this accident will place it into the residual risk category. However, this accident is proposed to be within the design basis of the confinement. Although this accident is of such low frequency as to be of dubious value in estimating on-site and off-site radiation doses (residual risk events are considered to be of such low probability that their risk is acceptable), it may be useful to consider such events while the designs of the cooling systems and the confinement continue to evolve, in order to enhance further the passive safety of the facility by uncovering any relative vulnerabilities and allowing the design to accommodate and/or eliminate them.

A preliminary target temperature history for this case is shown in Figure 1. Assuming that the beam and pumps are tripped at time zero, the pump coast down period would end at $\mathbf{4 5}$ seconds. Since the decay heat during this time would be about $1 \%$ of the operating power, the target actually cools to $62^{\circ} \mathrm{C}$ during the pump coast-down period. From 45 seconds to 90 seconds, the time at which the cavity is completely flooded, it is assumed that the target heats up adiabatically. At 90 seconds, the average temperature of spallation target is calculated to be $65.5^{\circ} \mathrm{C}$.

After the cavity has been flooded with cold water, the following mechanisms for the heat transfer from the $\mathrm{Pb}$ rods to the water in the basin are considered. The $\mathrm{Pb}$ rods transfer heat to the pressure tubes via conduction and natural convection (natural convection within each pressure tube, wherein the hot fluid from the central region rises upwards and cold fluid along the walls of the cold pressure tube moves downwards). The pressure tubes transfer energy to the cavity water via natural convection on the cavity side. It is important to note that due to the high thermal conductivity of the aluminum pressure tubes, the thermal resistance of the pressure tubes is negligible.

Since the failure of all active systems is assumed, the water in the cavity is assumed to heat up adiabatically due to heat transfer from the pressure tubes. Transient heat-transfer calculations show that the target reaches the saturation temperature of $101.42^{\circ} \mathrm{C}$ at 22.8 hours. From this time onwards, the heavy water within the pressure tubes would boil off. At approximately 31 hours into the accident, the water inventory from the unbroken loop drains as the upper header is uncovered. This $\mathrm{D}_{2} \mathrm{O}$ inventory (at $62^{\circ} \mathrm{C}$ ) would sweep through the target region and the upper header rapidly, displacing the saturated water with cold water from the unbroken loop. This would result in a rapid cool-down of the spallation target, but only for a very short time. The $\mathrm{Pb}$ rods and water would quickly reheat to saturation in less than $\mathbf{3 0}$ minutes.

Calculations show that at 37.2 hours, the cavity water would have reached $100^{\circ} \mathrm{C}$. Therefore, from this time forward, heat would be transferred from the pressure tubes to the cavity water via boiling heat transfer. At 43.6 hours into the accident, the $\mathrm{D}_{2} \mathrm{O}$ inventory in the 


\section{DISCLAIMER}

This report was prepared as an account of work sponsored by an agency of the United States Government. Neither the United States Government nor any agency thereof, nor any of their employees, make any warranty, express or implied, or assumes any legal liability or responsibility for the accuracy, completeness, or usefulness of any information, apparatus, product, or process disclosed, or represents that its use would not infringe privately owned rights. Reference herein to any specific commercial product, process, or service by trade name, trademark, manufacturer, or otherwise does not necessarily constitute or imply its endorsement, recommendation, or favoring by the United States Government or any agency thereof. The views and opinions of authors expressed herein do not necessarily state or reflect those of the United States Government or any agency thereof. 


\section{DISCLAIMER}

Portions of this document may be illegible in electronic image products. Images are produced from the best available original document. 
upper header of the target would have been boiled off and the rods would begin to be uncovered. At 48.4 hours the target region would have boiled dry. Until this time, the temperature of the spallation target had not exceeded the $\mathrm{D}_{2} \mathrm{O}$ saturation temperature. From this time onwards, the $\mathrm{Pb}$ rods heat up. At 50.4 hours into the accident, while the average target temperature has only reached $218.7^{\circ} \mathrm{C}$, the centerline temperature in the pressure tubes has reached the melting point of $\mathrm{Pb}\left(327.4^{\circ} \mathrm{C}\right)$. At this time, $\mathrm{Pb}$ in the central regions of the pressure tubes will begin to melt. When the average target temperature reaches $302.9^{\circ} \mathrm{C}$, heat transfer from the rods to the pressure tubes would be equal to the decay heat, assuming that the target had operated continuously for one year prior to the accident. This occurs at 57.3 hours. Since the decay heat would be continuously decreasing with time, from this time onwards the rods would cool. By this time, $26.8 \%$ of the lead in the target would have melted, relocated to the bottom header, frozen, and quenched. Since beyond this time the average rod temperature would continuously decrease, the system would be coolable. It is noted that due to the design of the structures above the target cavity and the target cavity flood tank, all the steam produced due to the boiling of cavity water would be condensed and returned to the cavity. Therefore, the cavity would remain flooded. It is also noted that after three days, only $2854 \mathrm{~kg}$ of water in the cavity would have been boiled off. If the assumption were made that the water boiled off from the cavity were not returned but just lost as steam, the decrease in the target cavity water level after three days would be approximately $15 \mathrm{~cm}$.

Until this point, it has been assumed that none of the forced cooling systems has been operational or available to aid in decay-heat removal from the spallation-target pressure tubes. This is, of course, an extreme assumption. Only the target cavity flood system was assumed to work. The systems that have been neglected include both Source Residual Primary Cooling System (SRPCS) loops (1-MW capacity each), the Target Cavity Flood System (TCFS) recirculating heat exchanger (1-MW capacity), both Window Primary Cooling System (WPCS) loops ( $0.5 \mathrm{MW}$ each), and the Blanket Primary Cooling System (BPCS) loop which is submerged in the flooded cavity (ultimate total heat capacity is $28 \mathrm{MW}$ ). Resumption of any one of these six coolant systems at any time prior to 42 hours into the accident would be sufficient to maintain the target cavity subcooled and to prevent the dryout of the spallation target pressure tubes in the SPCS, thus ensuring long-term coolability of the rods and recovery from the accident with no overheating damage to the spallation target. Resumption of one of these systems after the 42-hour point might lessen the extent of uncovery of the spallation target, potentially avoiding target overheating and minimizing the extent of damage to the rods.

As the $\mathrm{Pb}$ in the pressure tubes begins to melt (at $50.4 \mathrm{hrs}$ ), it relocates downward under gravity, and freezes and quenches in the inlet header, which is full of water. None of the quenched debris from the previously molten $\mathrm{Pb}$ from the damaged rods is expected to be released from the piping of the primary cooling system; once the melt is quenched, it is assumed to remain in the inlet header in a coolable configuration. If any of the pressure tubes were to fail due to contact with the melt at any time prior to 57 hours (termination of melting), the cavity water would flood into the break location, flood the pressure tubes to the level of the cavity water, and quench the overheated rods. This would immediately terminate the melting process and there would be no further release of radionuclides to the confinement. Provisions are being considered to preserve this possibility in the design of the SILC target for accident management purposes. 


\subsection{Source Term To Confinement}

During the melting period, the $\mathrm{Pb}$ is calculated to heat only to its melting point of $327^{\circ} \mathrm{C}$. The molten $\mathrm{Pb}$ from the damaged spallation rods would remain molten only as long as it took to fall under gravity into the water in the inlet header. This would be on the order of one second (calculated to be $0.65 \mathrm{sec}$ for a 2 meter fall). There is more than $2000 \mathrm{~kg}$ of $\mathrm{D}_{2} \mathrm{O}$ in the lower header, an order of magnitude more water in the lower header to freeze and quench the $\mathrm{Pb}$ debris than would be necessary. The melting of the spallation target would continue for seven hours (until 57.3 hours into the accident), at which time the heat losses would exceed the decay heat (which is continuously decreasing); thus, from $\mathbf{5 7 . 3}$ hours on, the target temperature would continue to decrease and melting would be arrested. The peak average temperature of the spallation target was calculated to be just $303^{\circ} \mathrm{C}$. Over this period of seven hours of melting, it is calculated that $27 \%$ of the $\mathrm{Pb}$ would have been melted $(6600 \mathrm{~kg}$ of $\mathrm{Pb}$ ) and that it would have required the vaporization of $162.5 \mathrm{~kg}$ of water to freeze and quench this mass of debris in the inlet header. Since the cross-sectional area for upflow in all the source pressure tubes is $0.36 \mathrm{~m}^{2}$, this results in an average steam velocity through all the target pressure tubes of approximately $3 \mathrm{~cm} / \mathrm{s}$. (Note: the cross-sectional area for flow in all of the 33 pressure tubes is $0.36 \mathrm{~m}^{2}$ and the coolant volume in all the tubes is $0.753 \mathrm{~m}^{3}$ ). Some of the parameters needed for the VSWAG code calculations of radionuclide release are summarized below:

Gas stream:

Melt temperature:

Average $\mathrm{Pb}$ melting rate:

Total steam flow rate:

Total cross-sectional flow area

in all pressure tubes:

Total flow volume in all

pressure tubes:
Steam at 1 bar and $100^{\circ} \mathrm{C}$

$327^{\circ} \mathrm{C}$

$0.26 \mathrm{~kg} / \mathrm{s}$

$6.45 \mathrm{gm} / \mathrm{s}, 0.011 \mathrm{~m}^{3} / \mathrm{s}, 3.0 \mathrm{~cm} / \mathrm{s}$

$0.36 \mathrm{~m}^{2}$

$0.75 \mathrm{~m}^{3}$

The driving force for the volatilization and transport of radionuclides from the molten $\mathrm{Pb}$ would be minimal. Since the $\mathrm{Pb}$ relocation process (free fall) will limit the time during which the $\mathrm{Pb}$ will be molten to the order of seconds, rate-limiting processes such as mass diffusion in the molten $\mathrm{Pb}$ will play a dominant role in limiting the vaporization release of radionuclides such as $\mathrm{Hg}$, and these factors must be considered in calculation of the source term. Those radionuclides that would be released from the melt would be carried upwards through the densely packed pressure tubes by the steam flow from the lower header of $3 \mathrm{~cm} / \mathrm{s}$, through the upper header and the SPCS piping, through the pump and heat exchanger, and finally out the break location and into the confinement air space. The source term to confinement is therefore dominated by the radionuclide burden of the $\mathrm{D}_{2} \mathrm{O}$ coolant at the time of the accident, plus the vaporization release from $\mathrm{Pb}$ for the limited time during which it is both liquid and exposed to air or steam.

\section{DISCLAIMER}

This report was prepared as an account of work sponsored by an agency of the United States Government. Neither the United States Government nor any agency thereof, nor any of their employees, makes any warranty, express or implied, or assumes any legal liability or responsibility for the accuracy, completeness, or usefulness of any information, apparatus, product, or process disclosed, or represents that its use would not infringe privately owned rights. Reference herein to any specific commercial product, process, or service by trade name, trademark, manufacturer, or otherwise does not necessarily constitute or imply its endorsement, recommendation, or favoring by the United States Government or any agency thereof. The views and opinions of authors expressed herein do not necessarily state or reflect those of the United States Government or any agency thereof. 
1.4 Large-Break Loss-of-Coolant Accident (LOCA): Total Failure of Active Cooling Systems Plus Non-Mechanistic Failure to Establish Natural Circulation in the Unbroken Loop, Basin Heat Exchanger Functional

The accident considered here is identical to the scenario considered above with the one exception that the target cavity circulation pump and heat exchanger are assumed to be available for heat removal from the flooded target cavity. The current design for the SILC target allows for a maximum heat rejection capability from the cavity water of $1 \mathrm{MW}$ if the circulation pump and heat exchanger are available for service. It is assumed at this stage of the design that these components will be safety grade but not part of the pressure boundary of the primary cooling system. Redundant motive sources are being considered for this heat-removal system which would ensure its availability under almost all imaginable accident conditions.

For this accident, as in the previous case, the SPCS water is calculated to reach saturation at 22.8 hours into the accident as shown in Figure 2. The target cavity water is calculated to reach saturation at 37.2 hours into the accident. During the time period from 24 to 43 hours, the heat generation rate in the SILC spallation target is nearly constant with time and is bounded by $0.16 \mathrm{MW}$. Each of the following three events, SPCS reaching saturation temperature, drainage of the unbroken loop, or cavity water reaching saturation, are expected to be detected by the target instrumentation systems, and any one may be used as a signal to start the target-cavity heat-rejection system. If the cavity circulation and heat-exchanger system is activated at any time prior to uncovery of the $\mathrm{Pb}$ target rods, the thermal transient in the target array would be arrested and the spallation target would be permanently cooled to a temperature below saturation. This scenario is depicted in Figure 2 for the case where the cavity heat-removal system is actuated at $\mathbf{3 7 . 2}$ hours upon detection of the target-cavity water reaching saturation. In this scenario, the target is permanently cooled to $50^{\circ} \mathrm{C}$. In the event of the sequence of events just described, the accident would be terminated with no damage to the target and no release of spallation products from the rods into the confinement. The source term to the confinement would be bounded by the circulating inventory of tritium in the SPCS.

\subsection{Key Phenomenological Points}

Even at the present stage of the design, certain conclusions can be drawn from the preliminary accident analyses presented above.

a. The time available for production of an airborne, in-confinement source term from the $\mathrm{Pb}$ is limited to the time that the $\mathrm{Pb}$ is molten, and in nearly all cases, this time will be relatively short. The allowable design-basis leakage limit for confinement will be influenced by this parameter.

b. Calculations presented in the previous section showed that even with the postulated failure of all loop-circulation mechanisms for heat removal, overheating would not occur for times on the order of 42 hours, given a flood. The heat-sink property of the cavity flood makes it a desirable design feature event if the loop-circulation function is lost. 
c. It appears to be relatively easy to allow for essentially all beam-off flooded scenarios within the confinement design basis, and it may be possible to allow for all beam-off unflooded scenarios as well.

\section{Source-Term Estimate Using the SNL VSWAG Computer Code}

The results of the thermal-hydraulics analysis described above were submitted to SNL for the calculation of the source term to the confinement that would result from this BDBE accident. No analysis tool exists for the computation of the environmental source term from the SILC target; therefore SNL applied the VSWAG computer program which they had developed for the ${ }^{3} \mathrm{He}$ target. Unfortunately the VSWAG code does not model a number of physical phenomena which are important in calculating reasonable source terms for the SILC target, such as melt alloying, condensed-phase mass diffusion, and aerosol trapping by water pools and water films, all of which represent significant barriers to mass transfer, vaporization, and mass transport for the SILC target. As a result, it is expected that the source terms calculated for the SILC target with the VSWAG code will be overestimated by several orders of magnitude.

A discussion of phenomenological and methodological conservatisms that were assumed by BNL in first performing the thermal analysis, as well as those applied by SNL in using the BNL thermal analysis for the purpose of generating a bounding environmental source term for the SILC target for this BDBE accident scenario, follows.

First, let us define some nomenclature. A phenomenological conservatism is defined as an assumption concerning a physical or chemical process for which there is incomplete understanding or modeling. The assumption is intended to result in an upper bound to the thermal-hydraulic system parameters to which the spallation target would be subjected or an upper bound on the release of spallation products from the damaged target. Such conservatisms are a result of incomplete or inadequate modeling and, as such, may be relaxed as the understanding of the physics and chemistry involved in the accident become more complete and more reliable. A methodological conservatism, on the other hand, is an assumption which is intended to introduce into the analysis a chosen path through the event tree which will ensure that an upper bound will be obtained based upon approach or choice. Such conservatisms are more like ground rules, and introduce a bias into the outcome which rarely can be relaxed based upon research results. Care should be taken before adopting methodological conservatisms without just cause.

Enumerated below are several of the major conservatisms that have been adopted in the thermal-hydraulic and source-term analyses for the BDBE accident previously mentioned for the APT SILC spallation target.

a. The thermal-hydraulic analysis began with the assumption that redundant active and passive cooling systems, including natural-circulation cooling, would fail to operate. Since the SPCS is designed to remove decay heat from the target with only one of two loops in natural circulation, this assumption ensures that the accident under consideration is beyond the design basis of the cooling systems. In fact, so many systems must simultaneously fail for this accident 
to occur that the probability of this scenario is so small as to be of no practical interest. However, we believe that it is within the design basis of the confinement and can be contained with negligible off-site consequences. (Methodological conservatism in thermal-hydraulics by BNL)

b. In developing the one-dimensional heat-transfer model for the heat-generating $\mathrm{Pb}$ rods, only radial heat transfer was considered. Axial conduction in the rods was neglected for simplicity, an assumption which certainly over-predicted the maximum rod temperature and the extent of melting damage to the $\mathrm{Pb}$ target. (Methodological conservatism in thermal-hydraulics by BNL)

c. The aluminum clad on the $\mathrm{Pb}$ spallation target rods is assumed to have no strength when the $\mathrm{Pb}$ melts. It is credited with no ability to prevent relocation of molten $\mathrm{Pb}$ despite experimental evidence to the contrary, nor to retain those spallation products which are gaseous or may vaporize. (Methodological conservatism in thermal-hydraulics and source term by BNL)

d. The spallation-product vaporization model (VSWAG) developed by SNL was created for the LANL ${ }^{3} \mathrm{He}$ target, and is of limited applicability to the BNL SILC target. For the ${ }^{3} \mathrm{He}$ target, spallation-product release would occur while the tungsten was still solid by oxidative vaporization from the surface; the geometry would be well characterized and mass diffusion in the solid tungsten is neglected. However, the authors of VSWAG point out that the model neglects physical and chemical phenomena which are of great significance for the SILC target. In their own words, the authors of the source-term model comment that their model, when applied to the SILC target, may generate results that are "potentially conservative, possibly excessively so." For instance, the resistance to vaporization by mass diffusion and alloy formation in both solid and molten $\mathrm{Pb}$ is neglected. The phenomenon of amalgamation of $\mathrm{Hg}$ along steel and aluminum surfaces of the pressure tubes and primary cooling system is neglected. Retention of $\mathrm{Hg}$ by water films along the piping is not considered. In short, no mass transfer or metallurgical barriers to spallation product vaporization and transport are considered. As an example, the source-term model allows for $\mathrm{Hg}$ to be released from both molten and solid $\mathrm{Pb}$ at its thermodynamic equilibrium vapor pressure into the rising steam in the pressure tubes. (Phenomenological conservatism in source term by SNL)

e. Vapor pressures are calculated by VSWAG for all spallation-product species as if they were caused by a pure bulk specimen of each product species, with no consideration for alloying effects. For such low mass fractions of these species, on the order of tens of grams for $\mathrm{Xe}, \mathrm{Kr}, \mathrm{F}, \mathrm{I}$, and $\mathrm{Br}$, and $\approx 10$ kilograms for $\mathrm{Hg}$ and $\mathrm{Tl}$, in a matrix of 22,000 kilograms of $\mathrm{Pb}$ (mass fractions on the order of $10^{-4}-10^{-6}$ or less), vapor-pressure modeling may be inappropriate. (Phenomenological conservatism in source term by SNL)

f. In the calculation of release fractions of spallation products from the SILC target, several extraordinary conservatisms have been invoked. First, release fractions for $\mathrm{Kr}, \mathrm{Xe}, \mathrm{F}$, $\mathrm{I}$, and $\mathrm{Br}$ were integrated over 30 hours following the onset of target damage although the molten $\mathrm{Pb}$ containing these isotopes was specified by the thermal-hydraulic analysis to be falling into the water-filled inlet plenum after a fall-time of less than one second. The molten $\mathrm{Pb}$ would be permanently quenched once it fell into the water. The release fraction for $\mathrm{Hg}$ was integrated 
for seven hours ... it too would be terminated by the quench of the $\mathrm{Pb}$ in the water. It was deemed appropriate by SNL to integrate the release from the damaged SILC target over the same 30 hour period that release from the ${ }^{3} \mathrm{He}$ target was calculated for purposes of comparison. But material from a damaged SILC target would only be molten for seconds at most. Furthermore, in integrating the release fractions for these spallation products from the damaged SILC target, release was allowed to occur not only from the $27 \%$ of the target that was calculated to melt but also from the $73 \%$ of the target that remained solid. In other words, release was calculated from the entire target mass, not just the molten mass. The release fractions so integrated were equal to 1.0 (complete release) for Iodine (and assumed to be equal to 1.0 for $\mathrm{Kr}, \mathrm{Xe}, \mathrm{F}, \mathrm{I}$, and $\mathrm{Br}$ isotopes and for tritium), and 0.017 for isotopes of $\mathrm{Hg}$. As a result, it is not methodologically possible to reduce the release of tritium, halogens, or noble gases from the SILC target below the SNL assumption of total release $(R F=1.0)$, regardless of the accident, thermal-hydraulic conditions, or duration of the accident. The only spallation product whose release can be mitigated is Hg. (Methodological conservatism in source term by SNL)

The source term that was calculated by SNL with VSWAG for the SILC target after a one-year irradiation is shown in Table 1. The source term that would result if release were limited to only the damaged portion of the target is also given in Table 1. Relaxation of the conservative assumption which allows for the release of spallation products from the entire target, instead of only the damaged portion, is not only technically reasonable but is also still bounding due to the conservatisms that would remain in the thermal-hydraulic and source-term calculations. Since there apparently are no plans to develop a version of VSWAG which would address the mass-transfer limitations that would apply to the SILC target as discussed in (d) above, it is appropriate that the assumption just discussed be relaxed, and that BNL demonstrate that the resulting source term estimated on the basis of the portion of the target which is damaged is conservative and bounding. This is currently being done by experiment and the results of a set of the experimental results are discussed in the following section.

\section{Mercury-Vaporization Source-Term Experiment}

\subsection{Purpose and Scope}

In order to quantify the environmental impact of the proposed Accelerator Production of Tritium (APT) Spallation Induced Lithium Conversion (SILC) facility, it is necessary to know the rate of volatilization of elemental $\mathrm{Hg}$ from molten $\mathrm{Pb}$. In view of the extremely conservative calculations by SNL (via the VSWAG computer code), involving both the phenomenological and methodological conservatisms, direct experiments were deemed necessary. Consistent with the LBLOCA accident scenario described in Section 1.2, the objective of these tests is to measure the fraction of $\mathrm{Hg}$ inventory released when droplets of molten $\mathrm{Pb}$ doped with a known concentration of $\mathrm{Hg}$ fall through a controlled environment. The experimental parameters to be varied are the initial concentration of $\mathrm{Hg}$ in the $\mathrm{Pb}$ and the melt temperature. The current scoping tests are limited to a maximum melt temperature of $346^{\circ} \mathrm{C}$. 


\subsection{Experimental Apparatus and Method}

A schematic of the experimental apparatus is shown in Figure 3. The test section consists of a glass-lined 50.8-mm-diameter stainless-steel pipe that is $1-\mathrm{m}$ high. A stainless-steel melt vessel of identical internal diameter is bolted on top of the test section. The bottom of the melt vessel consists of a $12.7-\mathrm{mm}$ thick stainless steel plate with a $3.175-\mathrm{mm}$ hole at the center. This small opening between the melt vessel and the test section is blocked by a conical stainlesssteel plunger. Two thermocouples and a melt stirrer are placed in the melt vessel through openings in the top cover of the melt vessel. Cylindrical radiant heaters surround the melt vessel. For simplicity, this heater, the heaters for the test section and tubing, the thermal insulation, and the thermal control system are not shown in this figure. Since the experiment entails the injection of molten droplets from the melt vessel to the test section, make-up gas must be supplied to the melt vessel. This is accomplished by connecting a compressed nitrogen supply via a pressure regulator and a flow control valve to the top cover of the melt vessel. The connecting tubing is heated and insulated.

The test section has two viewing ports to enable the observation and monitoring of the melt droplets (molten $\mathrm{Pb}$ doped with a known concentration of $\mathrm{Hg}$ ) during the experiment. Three thermocouples on the surface of the test section are used to control the test section temperature. A melt receptacle is placed in the bottom of the test section to collect the melt droplets. At the end of the experiment, this receptacle can easily be removed by unbolting the flange at the bottom of the test section. During the experiment hot air at a controlled flow rate and temperature is delivered to the test section bottom via an opening at an elevation just above the melt receptacle. An outlet port for the hot air is provided at the top of the test section.

Any $\mathrm{Hg}$ vapor that might be released from the molten droplets within the test section during the experiment will be carried off by the flowing hot air through the test section. In order to detect and extract this $\mathrm{Hg}$ from the air stream, the hot air is passed through three condensers and a water pool. All tubing downstream of the point $G$ in Figure 3 is made of glass. As an added precaution, to ensure that no $\mathrm{Hg}$ vapor is released to the laboratory environment in the event of an accidental breakage of glass tubing, the entire experimental apparatus resides in a hood.

The experimental procedure is initiated by compiling thin $\mathrm{Pb}$ strips with a total mass of $1-\mathrm{kg}$. The $\mathrm{Pb}$ strips are cut from a $99.9 \%$ pure chemical-grade $\mathrm{Pb}$ sheet. A calibrated Sartorius Model 3862 electronic balance is used to measure the total mass of $\mathrm{Pb}$ strips. The $\mathrm{Pb}$ strips are then placed in the melt vessel and the test section and the melt vessel are then heated. Hot air is circulated through the test section at a known flow rate and temperature as shown in Figure 3. The target air velocity in the test section is $10 \mathrm{~cm} / \mathrm{s}$. The set points on the temperature controllers are set so that the test section, the melt in the meit vessel, and the hot air injected into the test section are nominally at the same temperature. During this heat-up phase, the bypass valve V1, located upstream of the first condenser, is opened and the valve V2 is closed so that no hot air flows through the condenser during this phase. The mass of a given quantity (2-g to $10-\mathrm{g}$ ) of $\mathrm{Hg}$ in a petri dish is measured by a calibrated Mettler Model H51AR balance. The same balance, which has a standard deviation of $\pm 0.01 \mathrm{mg}$, is also used to measure the initial mass of the empty petri dish and a syringe. 
Upon attainment of steady state, the valve V2 is opened and the valve V1 is closed. Then, the pre-measured mass of $\mathrm{Hg}$ is injected into the molten pool of $\mathrm{Pb}$ in the melt vessel by means of a syringe. The stirrer in the melt vessel is used to mix the $\mathrm{Hg}$ in the molten pool for a few seconds, and is then locked in a position above the melt free surface. The experiment is initiated by lifting the plunger and allowing the molten droplets to fall through the test section at a controlled rate. The typical average melt flow rate is $0.8 \mathrm{~g} / \mathrm{s}$ or about 5 drops per second. It is estimated that the flight time of melt droplets through the test section is greater than 0.43 seconds. The molten droplets fall into a melt receptacle at the bottom of the test section. Any $\mathrm{Hg}$ released from the molten droplets is carried off by the flowing hot air and is trapped by the condensers.

At the end of the test, all the electrical heaters are de-energized and the air flow is terminated. After the test apparatus has cooled, the melt receptacle is removed from the test section. In addition, any $\mathrm{Hg}$ collected in the condensers would then be weighed.

\subsection{Results and Discussion}

For the purpose of quantifying the environmental impact of the proposed APT-SILC facility, experiments were conducted to measure the fraction of $\mathrm{Hg}$ inventory released when droplets of molten $\mathrm{Pb}$, doped with a known concentration of $\mathrm{Hg}$, fall through a controlled environment. The temperature of molten droplets ranged from $335^{\circ} \mathrm{C}$ to $346^{\circ} \mathrm{C}$, and the concentration of $\mathrm{Hg}$ in the droplets ranged from 0.2 mass $\%$ to 1.0 mass $\%$. By comparison, after a 1-year cycle, the concentration of $\mathrm{Hg}$ in the APT-SILC target rods would be 0.03 mass $\%$. In view of the very small concentrations of $\mathrm{Hg}$ in the APT-SILC target rods, higher concentrations of $\mathrm{Hg}$ were deliberately used for the experiments to improve the reliability of measurements. The test conditions and the results of the experiments are summarized in Table 2.

Direct observation of condensers, which are designed to trap any released $\mathrm{Hg}$ during the experiments, showed no $\mathrm{Hg}$ to be present at the end of every test. Chemical analysis of the solidified material collected at the bottom of the test section by the Inductively Coupled Plasma Atomic Emission Spectrometry confirmed the conclusion that no $\mathrm{Hg}$ was released from molten droplets during the experiments (see Table 3). Since the concentration of $\mathrm{Hg}$ in the droplets during the experiments was larger than that for the APT-SILC target, and since the vaporization of $\mathrm{Hg}$ from molten $\mathrm{Pb}$ may only increase with increasing concentration of $\mathrm{Hg}$, the experimental results are conservative and it can reliably be concluded that no $\mathrm{Hg}$ would be released from the APT-SILC target rods that melt during a postulated LBLOCA scenario.

In view of the uncertainties in the measurement of mercury concentrations by the ICPAES, it could be argued that if only a very small fraction of $\mathrm{Hg}$ were released from the molten droplets during the experiments, all of the released $\mathrm{Hg}$ could have deposited on the walls of the test section upstream of the condensers. However, it should be noted that the walls of the test section were nominally at the same temperature as the melt and the hot air during the experiments, whereas during the postulated accident in the APT-SILC source, the walls of the pressure tubes, the top header, and the outlet piping would be much colder $\left(\approx 100^{\circ} \mathrm{C}\right)$ than the melt temperature or the steam $\left(\mathrm{D}_{2} \mathrm{O}\right)$ temperature. Thus the extent of $\mathrm{Hg}$ deposition on these 
walls of the APT source (assuming if any $\mathrm{Hg}$ was released from the molten source rod material) is likely to be much greater than that likely to have occurred during these experiments. In addition, visual observations of the glass liner at the end of experiments did not show any evidence of $\mathrm{Hg}$ deposition. Therefore, it is reasonable to conclude that no $\mathrm{Hg}$ vapor is likely to be released from the molten target rod material to the confinement atmosphere during a postulated LBLOCA accident scenario as discussed in Section 1.1.

\section{Conclusions}

While both the APT and the SILC Target designs are still evolving, evaluations of the performance of the reference designs under postulated accident conditions can be invaluable to the design-making process and further design efforts. In the case described here, which is clearly of very low likelihood, the worst-case impact would be a few thousand curies.

Because mercury is a primarily spallation product in a lead target, and it is known to be highly mobile in some metals, it has been a concem since design conception. The experiment described herein demonstrates that little (if any) mercury would escape from molten lead. This has important safety design implications for not only the APT SILC Target, but also for any lead spallation target. 
Table 1

Source Terms for LBLOCA in SILC Target with Failure of Active and Passive Cooling Systems

\begin{tabular}{|l|c|c|}
\hline Element & $\begin{array}{c}\text { VSWAG } \\
\text { 1-yr irradiation }\end{array}$ & $\begin{array}{c}\text { VSWAG*** } \\
\text { 1-yr irradiation: } \\
\text { release from damaged } \\
\text { target only }\end{array}$ \\
\hline $\mathrm{Hg}$ & 1997 & 539 \\
$\mathrm{Kr}^{* *}$ & 2254 & 609 \\
$\mathrm{Xe}^{* *}$ & 862 & 233 \\
$\mathrm{~F}^{* *}$ & 1039 & 281 \\
$\mathrm{I}^{*}$ & 468 & 126 \\
$\mathrm{Br}^{* *}$ & 775 & 209 \\
$\mathrm{H}^{3 * *}$ & 173 & 173 \\
& & $2170 \mathrm{Ci}$ \\
\hline
\end{tabular}

* VSWAG calculates release of entire inventory of iodine from the SILC spallation target and cooling system to the confinement $(R F=1.0)$.

** Source term methodology assumes the release fraction is total.

*** This column is equal to the VSWAG (2-yr irradiation) calculation multiplied by 0.27 to account for partial target damage. 
Table 2

Experimental Parameters and Results From the $\mathrm{Pb}-\mathrm{Hg}$ Source Term Experiment

\begin{tabular}{|c|c|c|c|c|c|c|c|c|c|}
\hline Run \# & $\begin{array}{c}\text { Mass of } \mathrm{Hg} \\
\text { (g) }\end{array}$ & $\begin{array}{c}\text { Mass of Pb } \\
\text { (g) }\end{array}$ & $\begin{array}{c}\text { Concentration } \\
\text { of } \mathrm{Hg} \text { in melt } \\
(\text { mass } \%)^{\circ}\end{array}$ & $\begin{array}{c}\text { Melt } \\
\text { Temperature } \\
\left({ }^{\circ} \mathrm{C}\right)\end{array}$ & $\begin{array}{c}\text { Air } \\
\text { Temperature } \\
\left({ }^{\circ} \mathrm{C}\right)\end{array}$ & $\begin{array}{c}\text { Test Section } \\
\text { Temperature } \\
\left({ }^{\circ} \mathrm{C}\right)\end{array}$ & $\begin{array}{c}\text { Air } \\
\text { Velocity } \\
(\mathrm{cm} / \mathrm{s})\end{array}$ & $\begin{array}{c}\text { Average Melt } \\
\text { Flow Rate } \\
(\mathrm{g} / \mathrm{s})\end{array}$ & $\begin{array}{c}\text { Observed } \\
\text { Hg Release } \\
\text { Fraction }\end{array}$ \\
\hline 3 & 2.209 & 1000.3 & 0.220 & 335 & 338 & 335 & 10.5 & 0.70 & 0 \\
\hline 4 & 4.145 & 1000.8 & 0.412 & 341 & 338 & 335 & 10.3 & 0.80 & 0 \\
\hline 5 & 10.117 & 1000.5 & 1.001 & 337 & 338 & 335 & 10.2 & 0.75 & 0 \\
\hline 6 & 4.116 & 1000.1 & 0.410 & 343 & 340 & 341 & 10.5 & 0.80 & 0 \\
\hline 7 & 10.039 & 1000.5 & 0.993 & 344 & 344 & 341 & 10.3 & 0.86 & 0 \\
\hline 8 & 2.134 & 1000.1 & 0.213 & 346 & 348 & 341 & 10.4 & 0.84 & 0 \\
\hline
\end{tabular}

mass $\%=\frac{\text { mass of } \mathrm{Hg}}{\text { mass of } \mathrm{Hg}+\text { mass of } \mathrm{Pb}} \times 100$ 
Table 3

Mercury Concentration Measurements in the Solidified Samples From the Inductively Coupled Plasma Atomic Emission Spectrometry (ICP-AES)

\begin{tabular}{|c|c|c|c|}
\hline \multirow{2}{*}{ Run \# } & \multirow{2}{*}{$\begin{array}{l}\text { Prepared } \\
\text { concentration of } \\
\mathrm{Hg} \text { in the melt } \\
\text { (mass \%) }\end{array}$} & \multicolumn{2}{|c|}{ Measurements by ICP-AES } \\
\hline & & Sample source and location & $\begin{array}{l}\text { Measured concentration of } \mathrm{Hg} \\
\text { (mass \%) }\end{array}$ \\
\hline \multirow{3}{*}{3} & \multirow{3}{*}{0.220} & Melt Vessel & 0.33 \\
\hline & & Melt Receptacle-Top & 0.26 \\
\hline & & Melt Receptacle-Bottom & 0.19 \\
\hline \multirow{3}{*}{4} & \multirow{3}{*}{0.412} & Melt Vessel & 0.36 \\
\hline & & Melt Receptacle-Top & 0.41 \\
\hline & & Melt Receptacle-Bottom & 0.38 \\
\hline \multirow{3}{*}{5} & \multirow{3}{*}{1.001} & Melt Vessel & 0.85 \\
\hline & & Melt Receptacle-Top & 0.97 \\
\hline & & Melt Receptacle-Bottom & 0.94 \\
\hline \multirow{3}{*}{6} & \multirow{3}{*}{0.410} & Melt Vessel & 0.36 \\
\hline & & Melt Receptacle-Top & 0.40 \\
\hline & & Melt Receptacle-Bottom & 0.38 \\
\hline \multirow{3}{*}{7} & \multirow{3}{*}{0.993} & Melt Vessel & 0.66 \\
\hline & & Melt Receptacle-Top & 0.85 \\
\hline & & Melt Receptacle-Bottom & 0.91 \\
\hline \multirow{3}{*}{8} & \multirow{3}{*}{0.213} & Melt Vessel. & 0.21 \\
\hline & & Melt Receptacle-Top & 0.26 \\
\hline & & Melt Receptacle-Bottom & 0.26 \\
\hline
\end{tabular}


Figure 1. APT SILC SYSTEM: LBLOCA IN COLD LEG, IMMEDIATE BEAM TRIP, NO NATURAL CIRCULATION IN UNBROKEN LOOP: BASIN HEAT EXCHANGER NON-FUNCTIONAL

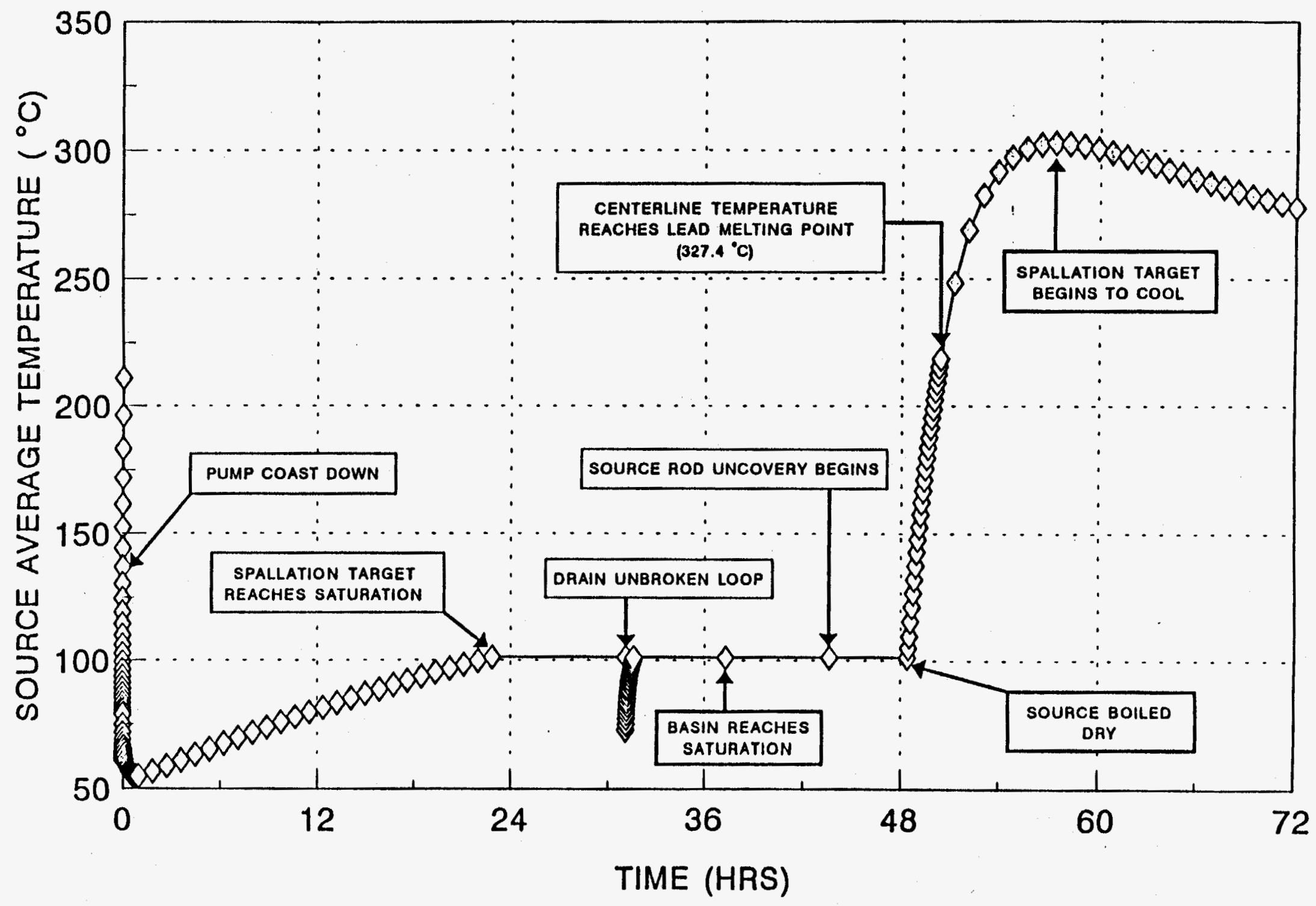


Figure 2. APT SILC SYSTEM: LBLOCA IN COLD LEG, IMMEDIATE BEAM TRIP, NO NATURAL CIRCULATION IN UNBROKEN LOOP: BASIN HEAT EXCHANGER FUNCTIONAL

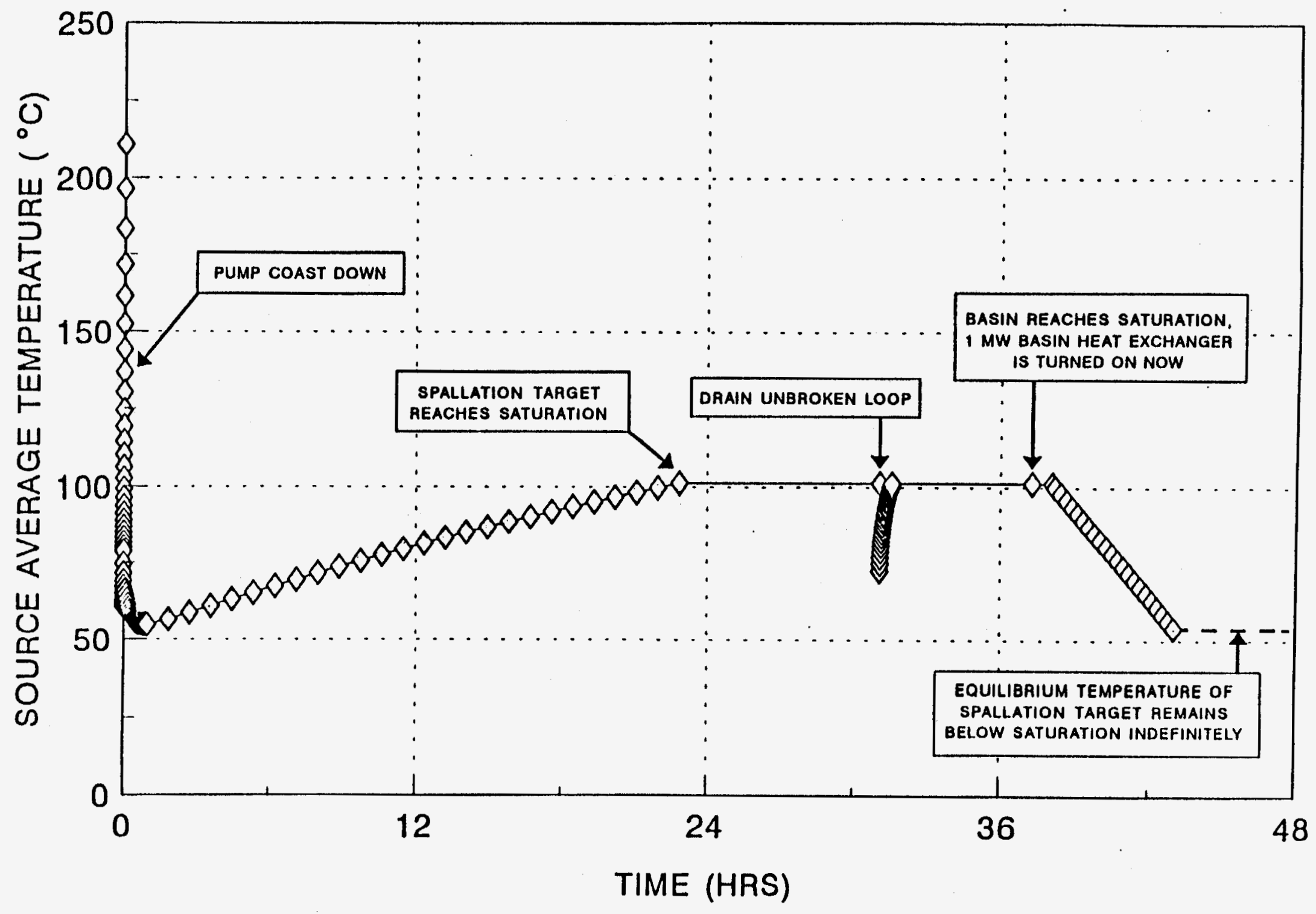




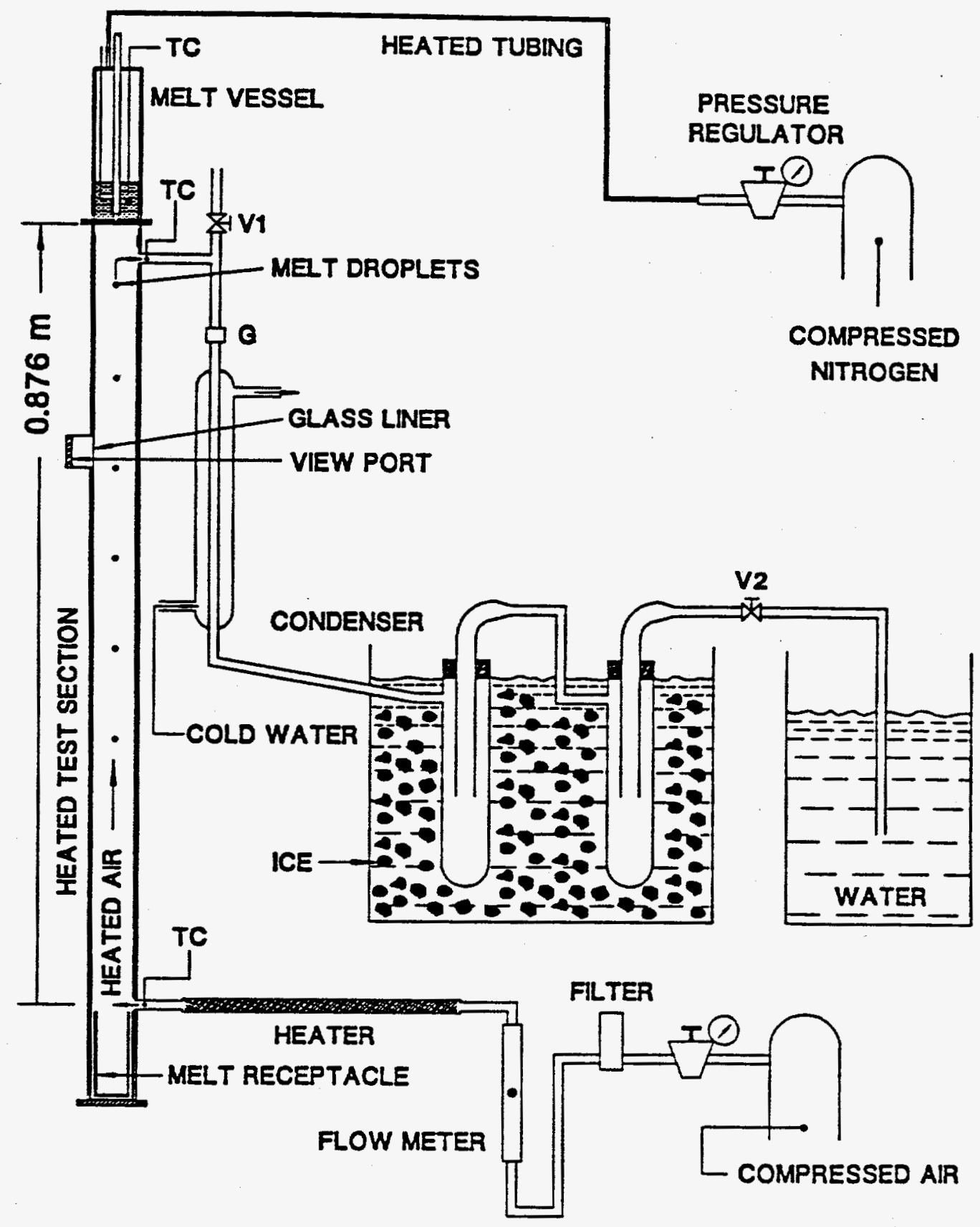

Figure 3. A schematic of the experimental apparatus. 